\title{
Some remarks on the origin of seismic anisotropy in the D" layer
}

\author{
Shun-ichiro Karato \\ Department of Geology and Geophysics, University of Minnesota, Minneapolis, MN 55455, U.S.A.
}

(Received April 7, 1998; Revised July 1, 1998; Accepted July 2, 1998)

\begin{abstract}
Physical mechanisms of seismic anisotropy in the D" layer are examined based on seismological and mineral physics observations. The results of body-wave seismology on the fine structure of the D" layer and of mineral physics studies on the elastic constants and the lattice preferred orientation in lower mantle minerals as well as the shape preferred orientation of melt pockets are taken into account. Evidence of large but depth (pressure)-dependent elastic anisotropy of lower mantle minerals, particularly $(\mathrm{Mg}, \mathrm{Fe}) \mathrm{O}$, and of tilted shape preferred orientation of sheared partial melts is summarized. It is shown that both shape preferred orientation of partial melts (or iron-rich secondary phases) and lattice preferred orientation of minerals with well-documented slip systems are difficult to reconcile with seismological observations. However, lattice preferred orientation of highly anisotropic mineral, $(\mathrm{Mg}, \mathrm{Fe}) \mathrm{O}$, is consistent with most of the seismic observations if the dominant glide plane under the D" layer conditions is $\{100\}$ rather than $\{110\}$ as observed at lower pressures. Such a change in glide plane in $\mathrm{MgO}($ or $(\mathrm{Mg}, \mathrm{Fe}) \mathrm{O})$ is likely to occur as a result of pressure-induced change in elastic anisotropy and/or in the nature of chemical bonding (and possibly due to high temperatures). Both solid-state and partial melt mechanisms of anisotropy imply that the $V_{\mathrm{SH}}>V_{\mathrm{SV}}\left(V_{\mathrm{SV}}>V_{\mathrm{SH}}\right)$ polarization anisotropy means horizontal (vertical) flow. In the solid-state mechanism, significant $V_{\mathrm{SH}}>V_{\mathrm{SV}}$ in the D" layer beneath the circum-Pacific (Alaska and the Caribbean) implies horizontal shear at high stress caused presumably by the collision of subducting materials with the core-mantle boundary. Highly variable anisotropy beneath the central-Pacific can be attributed to solid-state fabrics caused by a complicated threedimensional flow presumably related to the upwelling of plumes, but anisotropy in this region could also be attributed to the shape preferred orientation of melt pockets the presence of which is suggested by very low average velocities.
\end{abstract}

\section{Introduction}

The D" layer is a bottom boundary layer of convecting mantle and therefore is a key to a number of questions on the dynamics and evolution of the Earth. For example, it has been suggested that the D" layer may be a source of hotspots (Morgan, 1971; Stacey and Loper, 1983). Strong dynamical interaction of downgoing convection currents with the core-mantle boundary is also suggested by some numerical modeling (Honda et al., 1993) and seismic tomography (e.g., Woodhouse and Dziewonski, 1989; van der Hilst et al., 1997). Penetration of iron-rich materials to the D" layer through chemical reaction and/or by interfacial tension driven flow is also a possibility that may have influence on electro-magnetic interaction between the core and mantle (Knittle and Jeanloz, 1991; Poirier and Le Mouël, 1992).

Seismology can provide the most precise and richest information on which to place constraints on these processes (e.g., Lay et al., 1998a,b). In addition to velocity heterogeneity (e.g., Williams and Garnero, 1996; Garnero et al., 1998), seismic anisotropy carries potentially important information on the dynamics of the solid Earth (Karato, 1989), but the interpretation of seismic anisotropy in the D" layer has been difficult because of poor understanding of mechanisms of anisotropic structure formation (e.g., Karato, 1998; Lay et al., 1998a,b).

Copy right(c) The Society of Geomagnetism and Earth, Planetary and Space Sciences (SGEPSS); The Seismological Society of Japan; The Volcanological Society of Japan; The Geodetic Society of Japan; The Japanese Society for Planetary Sciences.
The presence of anisotropy in the D" region has been recognized by several previous studies (Vinnik et al., 1989, 1995, 1998; Maupin, 1994; Kendall and Silver, 1996; Matzel et al., 1996; Garnero and Lay, 1997; Lay et al., 1998b). The presence of anisotropy is a remarkable feature particularly because the absence of anisotropy in most of the lower mantle is well documented (Kaneshima and Silver, 1992; Meade et al., 1995; Montagner and Kennett, 1996). Therefore the questions to be addressed are: (i) why is (some portion of) the D" layer anisotropic whereas the rest of the lower mantle is isotropic? and (ii) what is the relation between the geometry of anisotropy and the dynamics of that layer where anisotropy exists?

To answer these questions one needs to investigate the mineral physics of anisotropy. Mineral physics issues critical to anisotropy include: (i) elastic anisotropy of the lower mantle minerals, (ii) nature of deformation fabric in lower mantle minerals and (iii) the nature of alignment (shape preferred orientation) of secondary phases such as melt pockets by deformation. Significant progress has been made on these three issues during the last a few years. This paper reviews the results of recent mineral physics studies on these issues and discusses geodynamic implications of seismic anisotropy in the D" layer.

\section{Seismological Observations}

Seismological observations on anisotropy in the D" layer are summarized by Lay et al. (1998a,b). Most of the constraints on anisotropy have been obtained from the analysis of 
(A)

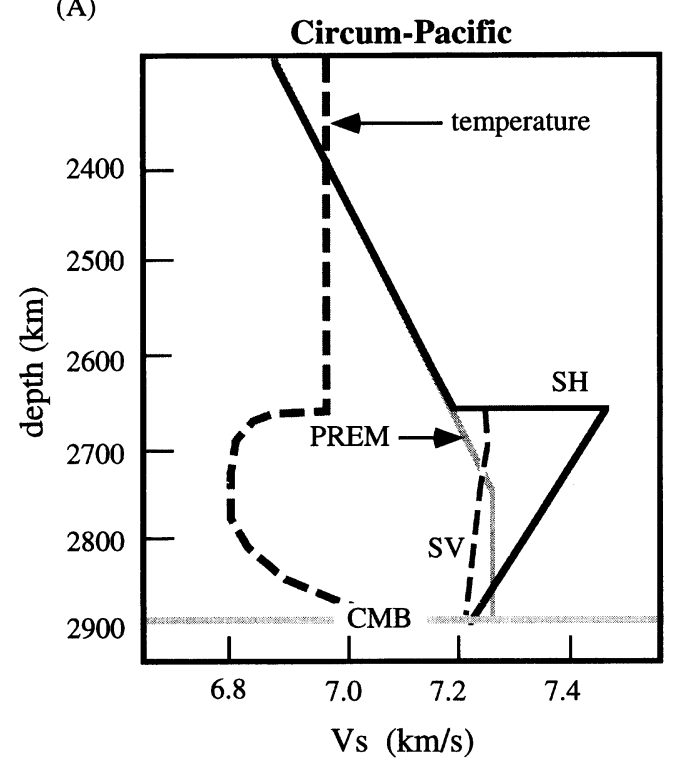

(B)

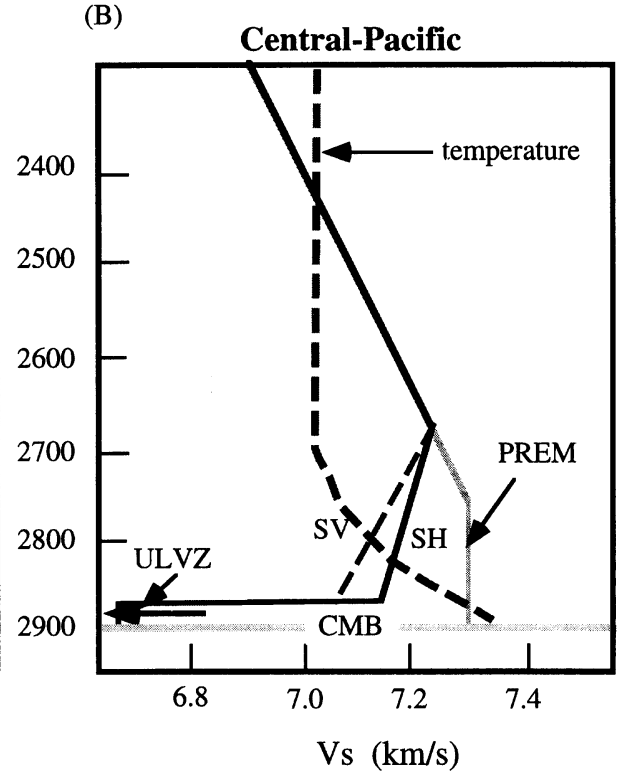

Fig. 1. Schematic diagrams illustrating shear wave velocity anisotropy and temperatures in the D" layer (A) beneath the circum-Pacific (Alaska and the Caribbean) and (B) beneath the central-Pacific (after Lay et al., 1998a,b). ULVZ stands for ultralow-velocity-zone in which shear wave velocity can be as much as $~ 30 \%$ lower than average (Williams and Garnero, 1996; Garnero et al., 1998). Anisotropy is strong near the top of the D" layer in the circum-Pacific but it is strong toward the bottom in the central-Pacific. Seismological observations are consistent with transverse isotropy, although azimuthal anisotropy with some specific symmetry cannot be ruled out (see text). Temperature distribution is highly schematic. Lower than average temperatures are expected in the circum-Pacific region where average velocities are higher than surrounding regions but temperatures are expected to be higher than normal in the central-Pacific.

polarization anisotropy of shear waves. Seismic waves that propagate nearly horizontally near the bottom of the mantle (grazing waves) such as $\mathrm{S}_{\text {diff, }}$ ScS, SKS, SPdKS etc. at large distance $\left(\Delta \sim 60-120^{\circ}\right)$ are used in these studies. Analyses of shear wave splitting as well as waveform modeling are used to constrain the structure.

The key seismological observations on the anisotropy in the D" layer can be summarized as follows. (i) There is strong $V_{\mathrm{SH}}>V_{\mathrm{SV}}$ anisotropy $\left(V_{\mathrm{SH}}\right.$ and $V_{\mathrm{SV}}$ are velocities of horizontally or vertically polarized shear waves respectively) in the circum-Pacific regions (beneath Alaska and the Caribbean) where average velocities are higher than PREM. (ii) Anisotropy is weaker in regions of moderate to slow average velocities. (iii) The anisotropic structure is highly complicated in the central-Pacific region where average velocities are lower than PREM. Very large $V_{\mathrm{SH}}>V_{\mathrm{SV}}$ anisotropy $(\sim 10 \%)$ is suggested (Vinnik et al., 1998) whereas a region of $V_{\mathrm{SV}}>V_{\mathrm{SH}}$ anisotropy is also hinted (Ritsema et al., 1998). (iv) In the D" layer beneath circum-Pacific, anisotropy appears to occur mostly in the shallow portions of the D" layer whereas in the central-Pacific, anisotropy seems to be concentrated in the deep portions of the D" layer. (v) Transition from the isotropic to anisotropic region beneath Alaska and the Caribbean is sharp and there is a sharp increase in $V_{\mathrm{SH}}$ as one goes into the D" layer, whereas $V_{\mathrm{SV}}$ and $V_{\mathrm{P}}$ change less. (vi) There is no strong evidence of a velocity discontinuity in regions beneath central-Pacific except at the very bottom of the D" layer ("ultralow velocity zone"). (vii) In most cases, the seismological data are consistent with transverse isotropy because there is no evidence, in waveforms, of significant interaction between $\mathrm{SH}$ and $\mathrm{SV}$ waves and of the absence of significant shear wave splitting of vertically traveling waves such as SKS (Kendall and Silver, 1996). However, transverse isotropy is not well constrained and azimuthal anisotropy is suggested by some data (Winchester and Creager, 1997; Valenzuela and Wysession, 1998). A schematic diagram of velocity structures is shown in Fig. 1.

\section{Mineral Physics Observations Relevant to Seis- mic Anisotropy in the D" Layer}

I will consider two microstructures that can cause seismic anisotropy. One is the lattice preferred orientation (LPO) of elastically anisotropic minerals, and the other is the shape preferred orientation (SPO) of a two-phase mixture with different elastic moduli. The latter includes aligned melt pockets as well as laminated structures involving former oceanic crust or iron-rich materials that may penetrate from the core. I first review elastic anisotropy in lower mantle minerals, then discuss the deformation mechanisms in lower mantle minerals that determine the presence or absence of LPO, the nature of LPO in lower mantle minerals in the dislocation creep regime and finally the SPO in a deformed two-phase mixture.

\subsection{Elastic anisotropy of lower mantle minerals}

Although direct measurements of elastic constants under lower mantle conditions are still not possible, there has been major development in theoretical calculations and some indirect experimental estimation of elastic anisotropy under deep mantle conditions (Isaak et al., 1990; Duffy et al., 1995; Karki et al., 1997a,b). The results can be summarized as follows. (i) Most of the deep mantle minerals including $\mathrm{MgO}$ (or $(\mathrm{Mg}, \mathrm{Fe}) \mathrm{O}$ ) and $(\mathrm{Mg}, \mathrm{Fe}) \mathrm{SiO}_{3}$ perovskite are anisotropic. 
(ii) The effects of pressure on elastic constants are large. The elastic constants change from the top to the bottom of the lower mantle by $\sim 50$ to $\sim 200 \%$. In contrast, the change in elastic constants due to temperature is small, about $\sim 5$ $10 \%$ corresponding to a temperature change of $\sim 1000 \mathrm{~K}$. (iii) However, the change in elastic constants with pressure depends on individual elastic constants, and as a result, elastic anisotropy of a given mineral changes significantly with pressure.

In particular, one must note that $\mathrm{MgO}$, one of the simplest minerals in the mantle, is shown to have very large elastic anisotropy (Isaak et al., 1990; Karki et al., 1997a). Elastic anisotropy is large particularly for the shear moduli, which is due to the softening of $c_{44}$ associated with the instability of $\mathrm{B} 1$ (NaCl-type) lattice under high pressures. Such behaviour is common to many materials with the B1 structure (e.g., Anderson, 1995). As a result, the ratio of two shear moduli, $S=\left(c_{11}-c_{12}\right) / 2 c_{44}$, increases significantly with pressure (Fig. 2). Even the sign of the anisotropy changes: $S$ is less than 1 at low pressures, whereas $S$ is significantly larger than 1 at high pressures (anisotropy of $\mathrm{MgO}$ is weak in mid-lower mantle conditions, at around 1000-1500 km depth). Duffy et al.'s (1995) experimental study supports this notion. $\mathrm{MgSiO}_{3}$ perovskite is also elastically anisotropic (Karki et al., 1997b), but the magnitude of elastic anisotropy of perovskite is much

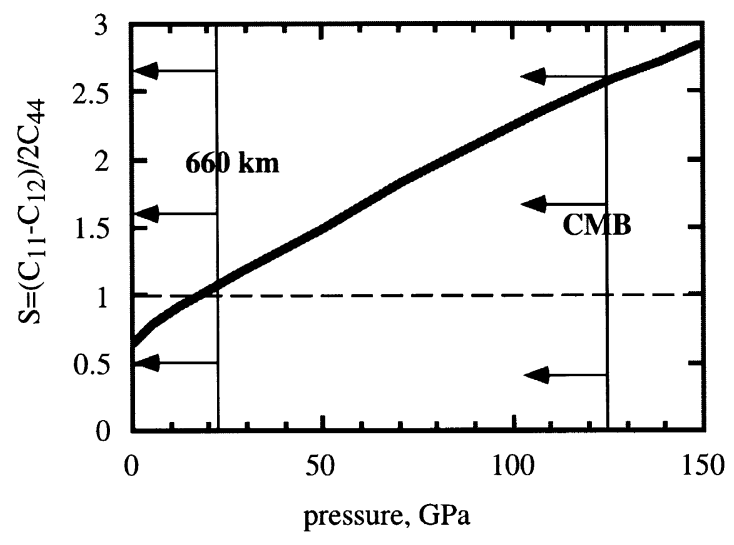

(A)

Fig. 2. Anisotropy of shear moduli (A) and seismic wave velocities (B) in single crystal of $\mathrm{MgO}$ at different pressures and at $T=0 \mathrm{~K}$ (elastic constants are from Karki et al., 1997a). Elastic constants in the shallow lower mantle $(P \sim 25 \mathrm{GPa}$ and $T \sim 2000 \mathrm{~K})$ and in the D" layer $(P \sim 125 \mathrm{GPa}$ and $T \sim 3000-4000 \mathrm{~K}$ ) correspond to those at $P \sim 0 \mathrm{GPa}$ and $T=0 \mathrm{~K}$ and at $P \sim 100 \mathrm{GPa}$ and $T=0 \mathrm{~K}$ respectively. (A) Anisotropy in shear moduli, $S=\left(c_{11}-c_{12}\right) / 2 c_{44}$, is plotted as a function of pressure (arrows indicate the shift of effective pressures corresponding to the $660 \mathrm{~km}$ boundary and the core mantle boundary (CMB) due to temperature effect). Note that $S$ is smaller than 1 at low pressures but increases with pressure and becomes larger than 1 at around 10-20 GPa. (B) The (001) cross sections of velocity surfaces at $P=0,20$, and $100 \mathrm{GPa}$ are shown. Thick curves show quasi-compressional (the highest velocity) and two quasi-shear wave velocities (the solid curves show the shear wave velocities with polarization vector parallel to the [001] axis, the dotted curves correspond to the velocities of quasi-shear waves with polarization nearly perpendicular to the [001] axis) respectively. Note that seismic anisotropy in $\mathrm{MgO}$ is large and changes significantly with pressure. Velocities of two (quasi) shear waves coincide each other for waves propagating along the $\langle 100\rangle$ directions. less than that of $\mathrm{MgO}$.

The results reported here are for $\mathrm{Mg}$-end members at $0 \mathrm{~K}$. To estimate elastic constants of minerals at lower mantle conditions, I make the following assumptions. (i) The effect of temperature is approximately accounted for by calculating elastic constants at the same density (Birch's law; Birch, 1961). This means that elastic constants at high $P$ and $T$ can be calculated from the theoretical values of elastic constants at high $P$ and $0 \mathrm{~K}$ by shifting pressure by $\Delta P=-\alpha K \Delta T$ where $\alpha$ is thermal expansion and $K$ is bulk modulus. For the $\mathrm{D}$ " layer, this correction is $\Delta P \sim-30 \mathrm{GPa}$. (ii) Addition of a small amount of Fe does not affect anisotropy. (iii) Anelastic relaxation, which is important for the interpretation of velocity heterogeneity (Karato, 1993), does not significantly affect elastic anisotropy. These hypotheses can be challenged. In particular, the effects of $\mathrm{Fe}$ on the elasticity must be investigated in more detail. However, the main conclusions of this paper are not very sensitive to these assumptions.

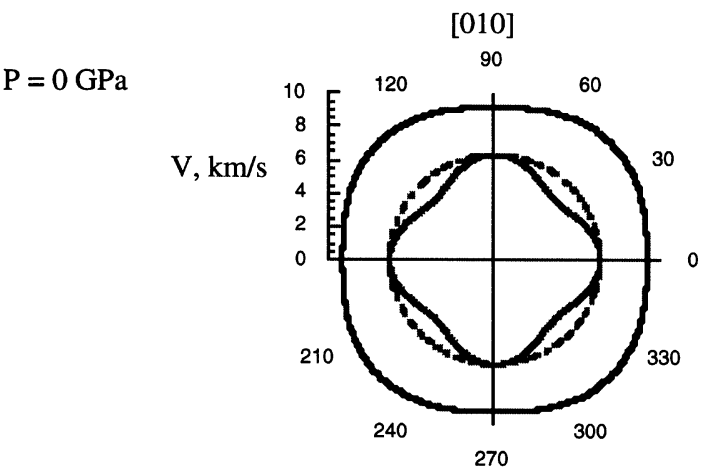

$\mathrm{P}=20 \mathrm{GPa}$
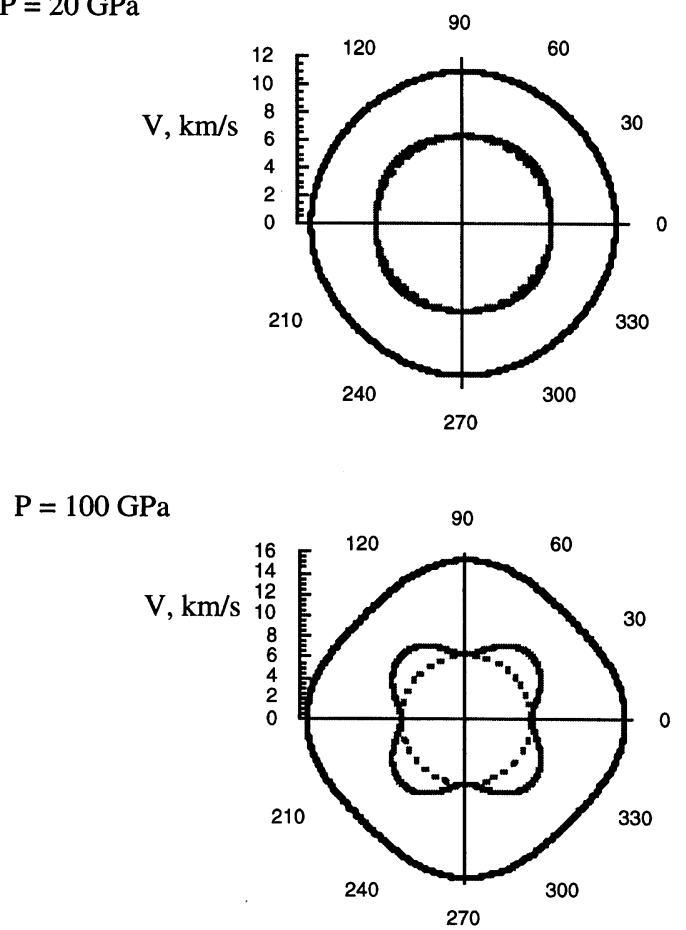

(B)

Fig. 2. (continued) 


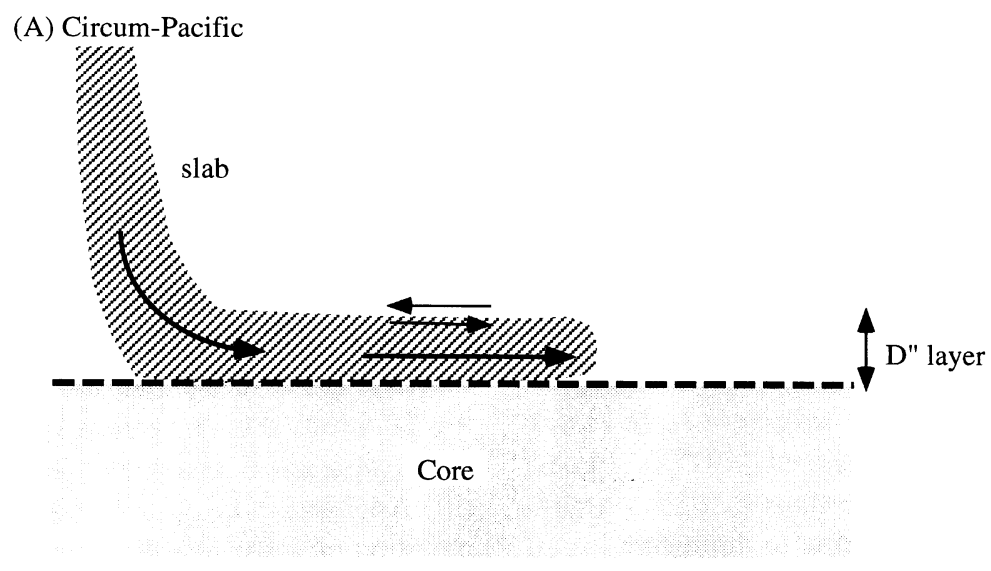

(B) Central-Pacific

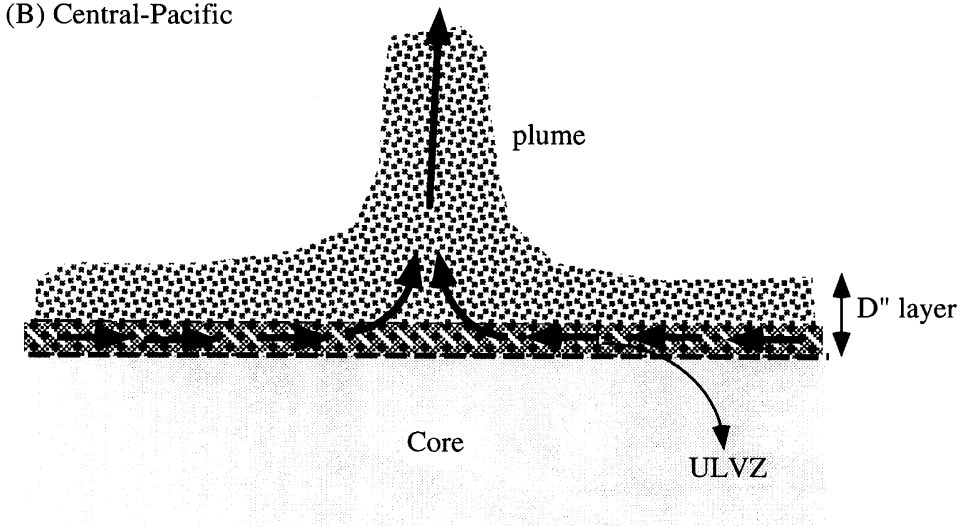

Fig. 3. Cartoon showing the flow pattern in the D" layer. (A) In the D" in the circum-Pacific, the flow pattern is governed by the collision with subducting cold materials with the core-mantle boundary. As cold materials squeeze into this layer, most of shear deformation occurs near the top boundary. Because the strain-rates and hence stress levels in this region are significantly higher than those in the surrounding areas, dislocation creep is likely to occur to cause significant lattice preferred orientation near the top boundary of the D" layer. (B) In the central-Pacific, the major driving force for flow in the D" layer is a large buoyancy force in the ULVZ which is hot and less dense. Therefore major shear deformation occurs near the bottom of the D" layer. The anisotropic structure thus formed may be either lattice preferred orientation (if stress is high enough) or shape preferred orientation of melt pockets. In both cases, as flow direction changes from sub-horizontal to sub-vertical, the nature of anisotropy will change, resulting in variable anisotropy.

\subsection{Deformation mechanisms of lower mantle minerals}

Three issues are important here. First, fabric formation depends on deformation mechanism. Deformation by diffusion creep or superplasticity does not result in fabric (e.g., Edington et al., 1976; Karato et al., 1995), whereas deformation by dislocation glide and/or twinning results in strong fabric. Transition from strong to weak fabric associated with the transition in deformation mechanisms has been demonstrated for olivine (Karato and Wu, 1993; Zhang et al., 1998) and in perovskite (Karato et al., 1995). In all cases, the conditions at which this transition occurs are within a range of conditions that may occur in the Earth (Karato, 1997, 1998). Second, the type of fabric (LPO) caused by dislocation glide or twinning depends on the crystallography of dominant slip systems and twinning (van Houtte and Wagner, 1985). Third, dominant slip systems (and the geometry of twinning) can change with deformation condition such as stress, temperature or pressure. This results in fabric transition which has been well documented for quartz (Tullis et al., 1973) and calcite (Wenk et al., 1973).

\subsection{Deformation mechanism maps}

The transition from an isotropic to an anisotropic structure can occur as a result of change in deformation mechanism. A change in deformation mechanism can be caused by a variety of reasons. Let us assume a power-law creep equation,

$$
\dot{\varepsilon}_{i}=A_{i}\left(\sigma^{n_{i}} / d^{m_{i}}\right) \exp \left[-H_{i}^{*} / R T\right]
$$

where $\dot{\varepsilon}_{i}$ is strain-rate, $T$ is temperature, $P$ is pressure, $\sigma$ is stress, $d$ is grain-size, $R$ is the gas constant, $A_{i}$ is the preexponential factor (insensitive to temperature and pressure), $H_{i}^{*}$ is the activation enthalpy, $n_{i}$ is the stress exponent and $m_{i}$ is the grain-size exponent for $i$-th mechanism. The transition conditions from one mechanism (mechanism 1) to the other (mechanism 2) are given by,

$$
\sigma=\left(\frac{A_{1}}{A_{2}}\right)^{\frac{1}{n_{1}-n_{2}}} d^{\frac{m_{1}-m_{2}}{n_{1}-n_{2}}} \exp \left[\frac{H_{1}^{*}-H_{2}^{*}}{\left(n_{1}-n_{2}\right) R T}\right] .
$$

For the case where mechanism 1 is dislocation creep and 2 is diffusion creep, we have $n_{1}>n_{2}$ and $m_{2}>m_{1}$. Therefore, dislocation creep, in which a strongly anisotropic structure 
is formed, tends to dominate under high stress (i.e., high strain-rate) and coarse grain-size conditions. The relative magnitude of activation enthalpy depends on the mechanism of deformation. When dislocation creep is controlled by dislocation climb and diffusion creep is controlled by grainboundary diffusion the activation enthalpy for dislocation creep is higher than that for diffusion creep. However, when lattice diffusion controls the rate of diffusion creep, then the activation energy for the two mechanisms will be similar.

Given the uncertainties in the activation enthalpies of creep and also in the magnitude of grain-size in the lower mantle, it is difficult to draw definitive conclusions as to the change in deformation mechanisms at this time. However, the difference in the magnitude of stress in the D" layer and the general lower mantle far away from D" is one of the likely causes for a change in deformation mechanisms. Recall that the convection in the Earth's mantle probably occurs at a high Rayleigh number (e.g., Jarvis and Peltier, 1989). In this case, flow is concentrated in the boundary layers where most of the buoyancy forces are concentrated. The contrast in strain-rate between inside the boundary layer $\left(\dot{\varepsilon}_{\mathrm{b}}\right)$ and in general regions $\left(\dot{\varepsilon}_{\mathrm{g}}\right)$ is given roughly by $\dot{\varepsilon}_{\mathrm{b}} / \dot{\varepsilon}_{\mathrm{g}} \sim L / \delta \sim\left[R a /(R a)_{\mathrm{c}}\right]^{1 / 3}$ where $L$ is the thickness of the layer and $\delta$ is the thickness of the boundary layer. Thus for a typical Rayleigh number of the Earth's mantle, $R a \sim 10^{7}$ (e.g., Jarvis and Peltier, 1989), one expects a factor of $\sim 10-15$ larger strain-rate and correspondingly higher stresses in the boundary layers than in the general regions of the lower mantle. The strain-rate in a part of the D" layer where significant LPO is formed may in fact be much higher than this estimate. For example, for the D" layer in the circum-Pacific where cold and therefore presumably strong materials collide with the coremantle boundary, deformation will occur mostly along the boundary between the cold slab materials and the layer above it (see Fig. 3). Thus the effective thickness of the layer of significant deformation is likely to be significantly smaller than the thickness of the D" layer. Likewise, in the D" layer beneath the central-Pacific, buoyancy forces for deformation are likely to be concentrated in the deeper and hotter portions of the D" layer. In both cases, strain-rates and hence stresses in the regions of localized flow are likely to be significantly higher than the simple model of boundary layer predicts. The high stresses in these regions will change the dominant deformation mechanism to dislocation creep (Fig. 4).

\subsection{Deformation fabrics and seismic anisotropy in de-} formed lower mantle minerals

Deformation fabrics in analog materials have been studied under low pressures and high homologous temperatures ( $T / T_{\mathrm{m}}, T$ : temperature, $T_{\mathrm{m}}$ : melting temperature) (Karato $e t$ al., 1995; Karato, 1998) or under high pressures but at room temperatures (Meade et al., 1995). Since deformation fabrics are closely related to deformation mechanisms which are in turn sensitive to temperatures, I will consider the results at high homologous temperatures.

For perovskite, the only study of deformation fabrics is on $\mathrm{CaTiO}_{3}$ (Karato et al., 1995; Zhang and Karato, 1998) which has the same crystal structure as $(\mathrm{Mg}, \mathrm{Fe}) \mathrm{SiO}_{3}$ perovskite (orthorhombic lattice with space group Pbnm). Strong LPO is formed by deformation in the dislocation creep regime, where the [100] axis becomes nearly parallel to the flow di-

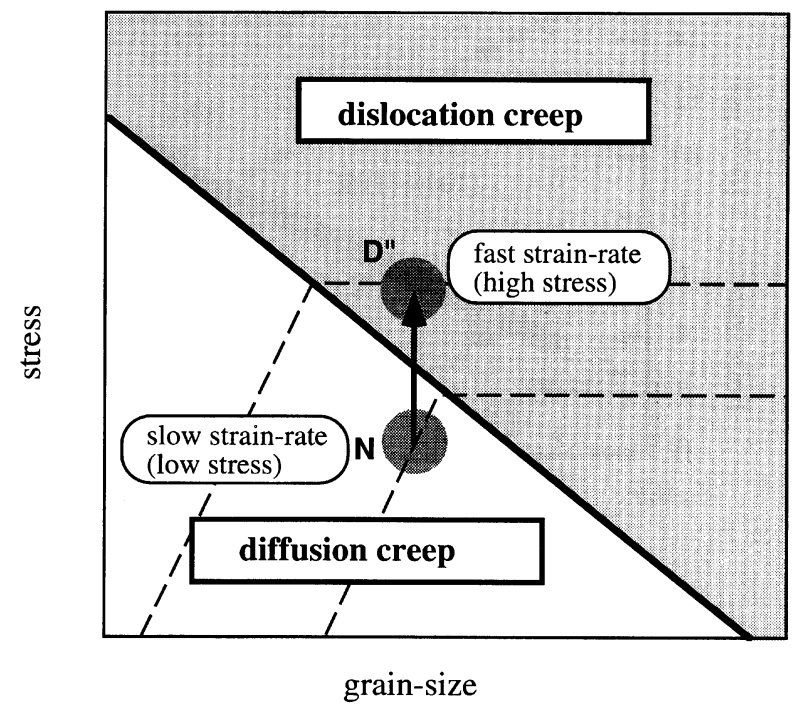

Fig. 4. A schematic deformation mechanisms map for minerals. For most of mantle minerals, the transition conditions between dislocation creep and diffusion creep are close to the conditions expected in the mantle (Karato, 1997). Therefore in relatively low stress regions in the mantle (Normal conditions), deformation may occur by diffusion creep whereas in relatively high stress regions such as the boundary layers (D" layer etc.), deformation is likely to occur by dislocation creep.

rection and the (010) plane become nearly parallel to the flow plane. The elastic constants of deformed perovskite aggregates have been calculated by averaging the LPOs of sheared $\mathrm{CaTiO}_{3}$ with the elastic constants by Karki et al. (1997b) (see also Karato, 1998). The LPO of perovskite will cause weak $V_{\mathrm{SH}}>V_{\mathrm{SV}}$ or $V_{\mathrm{SV}}>V_{\mathrm{SH}}$ anisotropy depending on the assumed elastic constants (Karato, 1998). The former is marginally consistent with some of the observations. However, this model would predict a general anisotropy but not the observed transverse isotropy and would cause significant $\mathrm{SH}-\mathrm{SV}$ interaction and shear wave splitting of vertically traveling waves which are inconsistent with the seismological observation.

Deformation fabrics for $\mathrm{MgO}$ corresponding to simple shear have not been studied. However, deformation fabrics in $\mathrm{NaCl}$ for simple shear were investigated (Franssen, 1993) which has the same type of dominant slip systems as $\mathrm{MgO}$ (Buerger, 1930). The $\{110\}$ planes become subparallel to the shear plane and the $\langle 111\rangle$ direction becomes subparallel to the shear direction which is consistent with the dominant slip systems, $\langle 110\rangle\{110\}$. Note, however, that in the $\mathrm{NaCl}$ structure, there is another set of slip systems, namely $\langle 110\rangle\{001\}$. The choice of the $\{110\}$ or $\{100\}$ plane appears to be dependent on the elastic anisotropy and also on the electronic polarizability of ions (Fig. 5). The elastic anisotropy changes significantly with pressure (Fig. 2). $\left(c_{11}-c_{12}\right) / 2$ which is the elastic constant for the shear along the $\{110\}$ plane increases more significantly with pressure than $c_{44}$ which is the elastic constant corresponding to the shear along the $\{100\}$ planes. A change in electronic polarizability with pressure could also cause a change in preferred glide plane. With small electronic polarizability, the $\{110\}$ planes are the easy 


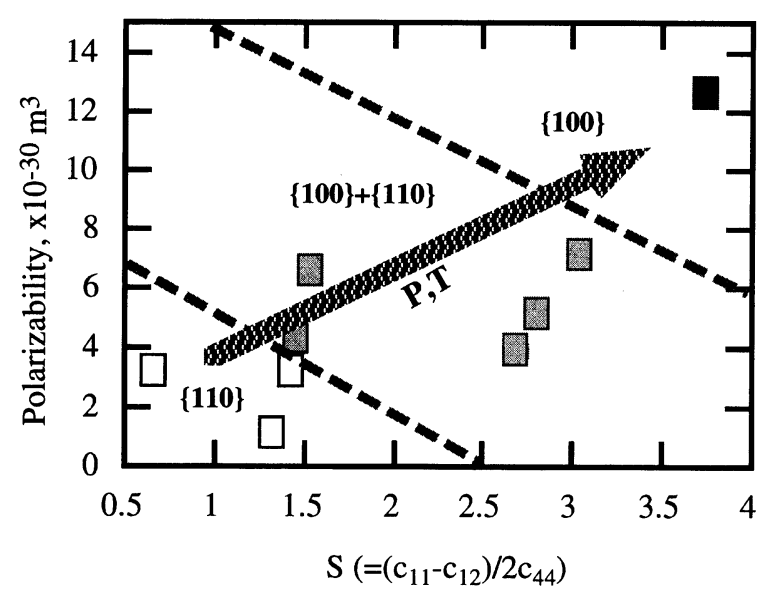

Fig. 5. Dominant slip planes in crystals with $\mathrm{NaCl}$ structure plotted as a function of elastic anisotropy $(S)$ and the sum of ionic polarizability. Crystals with large anisotropy ratio $S$ and polarizability tend to assume easy glide on $\{100\}$ planes. Effects of pressures and temperatures are shown schematically by an arrow. $\{100\}$ planes become dominant glide plane at high pressures and high temperatures. Data are from Buerger (1930) and Simmons and Wang (1971).

glide planes. However, for large polarizability, glide long the $\{100\}$ planes becomes easy. Because the electronic polarizability is likely to increase with pressure due to the change in chemical bonding to less ionic (e.g., Knittle and Jeanloz, 1986), one expects a change in fabric as pressure increases. Therefore glide on the $\{100\}$ plane will become easier at high pressures. High temperatures will also favor dislocation creep on the $\{100\}$ planes because of the higher activation energy for that slip system. Therefore it is likely that the relative easiness of the two slip systems, $\langle 110\rangle\{110\}$ and $\langle 110\rangle\{001\}$ will change with pressure and temperatures, the latter being easier at high pressures and temperatures. In the latter case, the $\{100\}$ plane becomes subparallel to the flow plane and the $\langle 100\rangle$ direction becomes subparallel to the flow direction. In addition, dynamic recrystallization, which occurs at high temperatures, may change the fabric (Rice, 1970; Skrotzki and Welch, 1983; Wenk et al., 1997). Thus I will consider two types of LPO associated with the dominant slip systems of $\langle 110\rangle\{110\}$ and $\langle 110\rangle\{001\}$ respectively.

When the $\langle 110\rangle\{110\}$ slip system dominates (under low pressures and/or low temperatures), the $\{110\}$ planes will be nearly horizontal. This causes $V_{\mathrm{SV}}>V_{\mathrm{SH}}$ polarization anisotropy for a horizontally propagating wave and a large shear wave splitting for a vertically traveling wave (Karato, 1998) both of which are inconsistent with seismological observation for the D" layer. On the other hand, if the $\{100\}$ planes are horizontal, as expected for horizontal shear at high pressures and high temperatures, then (e.g., Musgrave, 1970),

$$
\rho V_{\mathrm{SV}}^{2}=c_{44}
$$

and

$$
\rho V_{\mathrm{SH}}^{2} \sim C_{44}[1+B(S-1)(1-\cos 4 \phi)]
$$

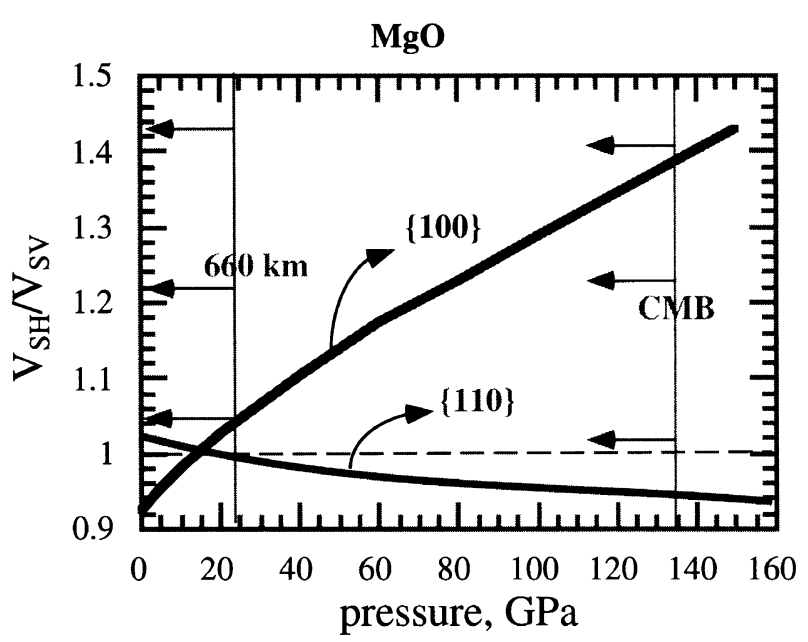

Fig. 6. $\quad V_{\mathrm{SH}} / V_{\mathrm{SV}}$ polarization anisotropy caused by the LPO of MgO. A case of transverse isotropy is considered in which the horizontal plane coincides with the dominant glide plane $(\{110\}$ or $\{100\})$. In the case of general anisotropy, $V_{\mathrm{SH}} / V_{\mathrm{SV}}$ polarization anisotropy depends also on the direction of wave propagation (see Fig. 2). Arrows indicate the shift of effective pressures due to temperature corresponding to the $660 \mathrm{~km}$ boundary and the core mantle boundary $(\mathrm{CMB})$.

hence

$$
\frac{V_{\mathrm{SH}}}{V_{\mathrm{SV}}} \sim[1+B(S-1)(1-\cos 4 \phi) / 2]
$$

where $B=\left(c_{11}+c_{12}\right) / 4\left(c_{11}-c_{44}\right), S=\left(c_{11}-c_{12}\right) / 2 c_{44}$ and $\phi$ is the direction of wave propagation measured from the [100] direction. Note that this predicts general anisotropy with four-fold symmetry along the vertical axis. Since the $\langle 100\rangle$ direction is the symmetry direction, there is no shear wave splitting for a vertically propagating waves through this structure (see Fig. 2). From Eq. (5), it can be seen that for the case of $S>1$ as in $\mathrm{MgO}$ at high pressures, $V_{\mathrm{SH}}>V_{\mathrm{SV}}$ (Fig. 6) $\left(V_{\mathrm{SV}}>V_{\mathrm{SH}}\right.$ for $S<1$ at low pressures). These results agree with seismological observations. Therefore the LPO of $(\mathrm{Mg}, \mathrm{Fe}) \mathrm{O}$ with the $\{100\}$ planes being horizontal is consistent with seismological observations.

The elastic constant tensor for a mixture of perovskite and $(\mathrm{Mg}, \mathrm{Fe}) \mathrm{O}$ and the resultant seismic anisotropy was also calculated. I used the Voigt average in this calculation and assumed a volume fraction of $20 \% \mathrm{MgO}$ and $80 \% \mathrm{MgSiO}_{3}$ perovskite. Both phases are assumed to deform by dislocation creep. The LPO of perovskite is assumed to be the same as that observed in $\mathrm{CaTiO}_{3}$ and that of $\mathrm{MgO}$ is arbitrarily assumed to be $1 / 3$ of the single crystal. Due to the large elastic anisotropy of $\mathrm{MgO}((\mathrm{Mg}, \mathrm{Fe}) \mathrm{O})$ in the D" layer, seismic anisotropy of the two-phase mixture is dominated by that of $\mathrm{MgO}((\mathrm{Mg}, \mathrm{Fe}) \mathrm{O})$. With appropriate mixtures, it is possible to obtain a model which is consistent with seismological observations $\left(V_{\mathrm{SH}} / V_{\mathrm{SV}} \sim 2-3 \%\right.$ and a shear wave splitting of a vertical traveling wave less than $0.2 \mathrm{sec}$ ).

\subsection{Alignment of melt pockets by deformation}

It has often been assumed that melt pockets will be horizontal when a partially molten material is sheared in a horizontal plane and hence anisotropic structure with transverse isotropy will result (Aki, 1968; Kendall and Silver, 1996). 


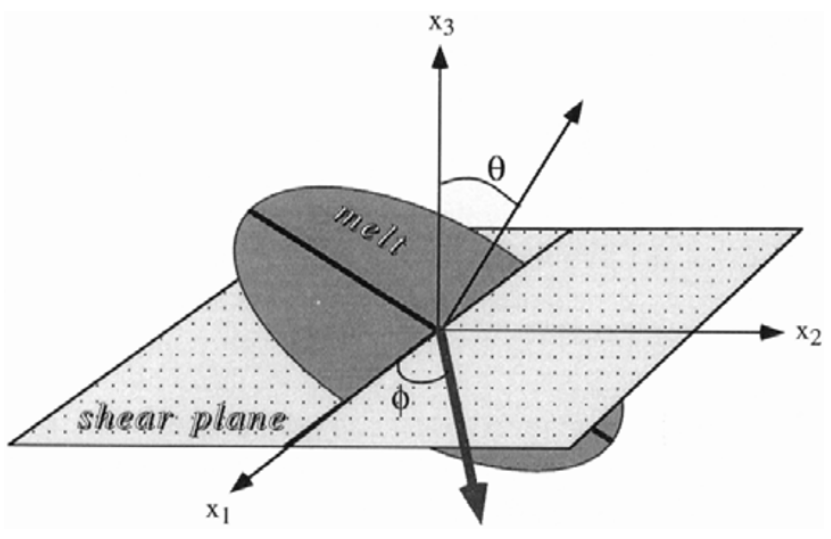

Fig. 7. Geometry of melt pockets in shear deformation. Both experimental study (Zhang et al., 1995; Karato et al., 1998) and theoretical modeling (Gay, 1968) show significant tilting of melt pockets due to shear deformation although the sense of tilting is opposite between the two cases.

However, actual geometry of melt (or low viscosity fluids) during deformation may be more complicated. Gay (1968) showed that if the viscosity of fluid inclusion is much less than that of the matrix, then the rotation of the long axis of fluid inclusions is much smaller than that of finite strain ellipsoid and significant deviation of orientation of melt pockets from shear direction occurs up to a significant strain (for example, the tilting angle of melt pocket from the shear plane is $\sim 20^{\circ}$ at $500 \%$ strain; Gay, 1968). Likewise, the recent experimental study in our laboratory showed that there is a significant angle between the long axis of melt pockets and the flow direction in deformed olivine-basalt melt system (Zhang et al., 1995; Kohlstedt and Zimmerman, 1996; Daines and Kohlstedt, 1997; Karato et al., 1998; see also Bussod and Christie, 1991). In this latter case, tilting of $\sim 20-25^{\circ}$ occurs to the direction opposite to the long axis of finite strain ellipsoid (antithetic to the shear direction).

Common to both cases is the significant tilting of the plane of melt pockets (Fig. 7). This causes an anisotropic structure that does not have transverse isotropy. To see this, let us assume that melt pockets have a circular shape with a tilting angle of $\theta$. Consider a seismic wave propagating in the horizontal plane along the direction defined by the angle $\phi$ (angle between the propagation direction and the cross section between melt pocket and the horizontal plane, see Fig. 7). The shear waves propagating through such a medium are split into two polarization directions, one in the plane of melt pocket (SH wave) and the other perpendicular to it (SV wave) (Hudson, 1981). For small anisotropy with a small tilting angle, one has,

$$
\rho V_{\mathrm{SH}}^{2}=\mu\left[1+A\left(\sin ^{2} \phi \cdot \sin ^{2} \theta-1\right)^{2}\right]
$$

and

$$
\rho V_{\mathrm{SV}}^{2}=\mu\left[1+A \sin ^{2} \phi \cdot \sin ^{2} \theta\right]
$$

where

$$
A=\frac{16}{3} f a^{3} \frac{\lambda+2 \mu}{3 \lambda+4 \mu}
$$

and $f$ is the number density of melt pockets, $a$ is their diam-

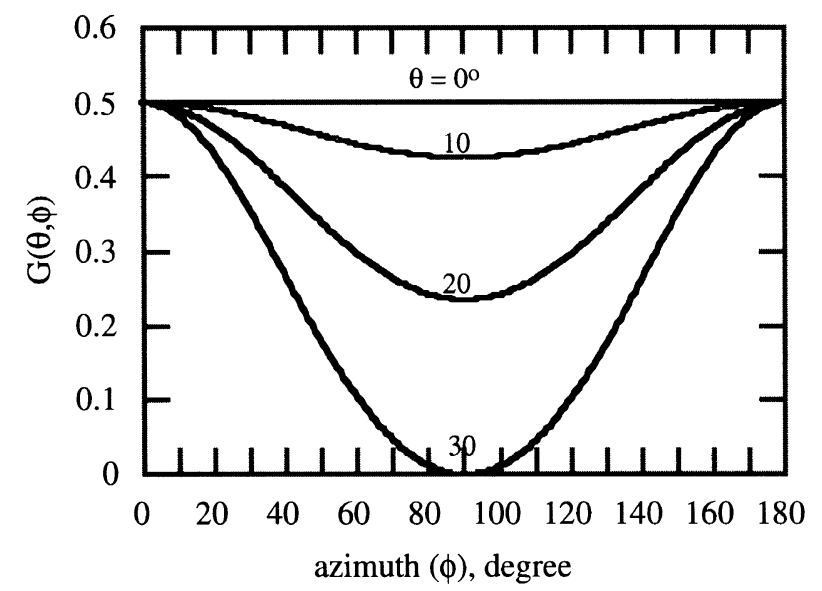

Fig. 8. Anisotropy function $G(\theta, \phi)$ for tilted melt pockets (Eq. (6) in the text). $\theta$ : angle of tilting of melt pockets from the horizontal plane, $\phi$ : orientation of propagation of seismic waves in the horizontal plane (see Fig. 7). For aligned melt pockets with some tilt, seismic wave velocity does not have transverse isotropy but rather depends on direction of propagation in the horizontal plane.

eter, $\lambda$ and $\mu$ are Lamé constants. Therefore,

$$
\frac{V_{\mathrm{SH}}}{V_{\mathrm{SV}}} \sim 1+A \cdot G(\theta, \phi)
$$

where

$$
\begin{array}{r}
G(\theta, \phi)=\frac{1}{2}\left[1-B_{2}(\theta)(1-\cos 2 \phi)\right. \\
\left.-B_{4}(\theta)(1-\cos 4 \phi)\right]
\end{array}
$$

with

$$
\begin{aligned}
& B_{2}(\theta)=(5 / 2) \alpha-2 \alpha^{2} \\
& B_{4}(\theta)=(1 / 2) \alpha^{2}
\end{aligned}
$$

where $\alpha=\sin ^{2} \theta$. Note that seismic wave velocity depends not only on the tilt $(\theta)$ of melt pockets but also on the azimuth $(\phi)$ of wave propagation and hence the structure is not transversely isotropic (Fig. 8). The azimuthal dependence is quite large even for a small tilt and the $\cos 2 \phi$ term dominates over the $\cos 4 \phi$ term. For example, for $\theta=20^{\circ}, B_{2}=0.265$ and $B_{4}=0.0068$.

Consequently, a vertically propagating wave through such a structure will show significant shear wave splitting. For example, for a tilting angle of $\theta=20-30^{\circ}$, if $\sim 2 \% V_{\mathrm{SH}} / V_{\mathrm{SV}}$ polarization anisotropy is observed for a horizontally propagating wave (e.g., Kendall and Silver, 1996), one gets $A \sim 0.1$ and therefore the shear wave splitting of $\sim 0.4-0.6 \mathrm{sec}$ will occur for a vertically traveling wave (I assume $\sim 200 \mathrm{~km}$ of an anisotropic layer). This significantly exceeds seismological observations that show less than $0.2 \mathrm{sec}$ shear wave splitting of SKS waves (Kaneshima and Silver, 1992; Meade et al., 1995).

\section{Discussion}

4.1 Why is (a part of) the D" layer anisotropic whereas most of the lower mantle isotropic?

The most straightforward hypothesis to answer this question that is consistent with mineral physics is to assume that 
some portion of the D" layer deform by dislocation creep whereas the rest of the lower mantle deforms by diffusion creep. A sharp jump in $V_{\mathrm{SH}}$ at the top of the D" layer may be due to the sharp change in anisotropic structure similar to the Lehmann discontinuity in the upper mantle (Karato, 1992). In this model, regions of the D" layer where significant anisotropy occurs correspond to regions of high stress.

Meade et al. (1995) argued, based on laboratory experiments at room temperature, that the lack of seismic anisotropy is due to unique properties of $\mathrm{MgSiO}_{3}$ perovskite that does not result in lattice preferred orientation due to deformation by any mechanisms including dislocation creep. Such a notion is incompatible with well established polycrystal plasticity theory (e.g., van Houtte and Wagner, 1985). In addition, application of the results at room temperature to the lower mantle where homologous temperature is considered to be high $\left(T / T_{\mathrm{m}} \sim 0.5-0.9\right)$ can not be justified, because deformation mechanisms in solids change significantly with temperatures. Furthermore, even if such an unusual behaviour might occur for $\mathrm{MgSiO}_{3}$ perovskite, it is well established that strong LPO will result if $\mathrm{MgO}$ ( or $(\mathrm{Mg}, \mathrm{Fe}) \mathrm{O}$ ) is deformed by dislocation creep (Rice, 1970). Because the presence of a significant amount of $(\mathrm{Mg}, \mathrm{Fe}) \mathrm{O}(\sim 20-30 \%$ for the pyrolite model; Ringwood, 1991) is highly likely in the lower mantle as suggested by the penetration of some slabs into the lower mantle (van der Hilst et al., 1997) and because $(\mathrm{Mg}, \mathrm{Fe}) \mathrm{O}$ is likely to have large elastic anisotropy in the deep lower mantle (Fig. 2), I consider that this model is difficult to maintain.

Lay et al. (1998a,b) considered that the deformation mechanisms in the lower mantle may change from diffusion creep in normal portions to dislocation creep in the D" layer due to high temperatures. As discussed before, the effects of temperature on deformation mechanisms in lower mantle minerals are poorly constrained. The most serious difficulty with this model is to explain the observation that a strong anisotropy is observed in the circum-Pacific where temperatures in the D" layer are likely to be lower than average.

I therefore conclude that the transition from isotropic to anisotropic structure that occurs in the D" layer is most likely due to LPO caused by deformation at high stress in that layer, particularly in the D" layer beneath the circum-Pacific, although the presence of aligned melt pockets is a possibility in the central-Pacific.

4.2 What is the cause for anisotropy and what does it tell us about the dynamics of the core-mantle boundary?

The present model implies that most of the anisotropy in the D" layer (except possibly the anisotropy in the D" layer beneath the central-Pacific) may be caused by LPO in $(\mathrm{Mg}, \mathrm{Fe}) \mathrm{O}$ with the $\{100\}$ being the dominant glide plane. In this case, $V_{\mathrm{SH}}>V_{\mathrm{SV}}$ means horizontal flow and $\mid V_{\mathrm{SH}}-$ $V_{\mathrm{SV}} / / V_{\mathrm{SH}}$ depends on the direction of propagation of seismic waves: the largest for the $\langle 110\rangle$ direction and the smallest along the $\langle 100\rangle$ direction.

An alternative model is the one by Kendall and Silver (1996) in which layered structure caused by SPO of melt pockets is considered to cause anisotropy. This model has, however, significant difficulties as follows. Firstly, if partial melting is responsible for anisotropy, then the average veloc- ity in anisotropic regions should be less than that of typical area. Although this may be the case for the D" layer beneath the central-Pacific, the average velocities in the circumPacific regions are higher than those in other typical areas. Second, melt pockets in sheared rocks are likely to be tilted, hence there should be significant interaction between $\mathrm{SH}$ and SV waves and significant shear wave splitting of a vertically traveling wave, which are inconsistent with the seismological observations. However, SPO of melt pockets cannot be ruled out as a cause for anisotropy in the central-Pacific where anisotropy appears to be strong in the very bottom of the D" layer where evidence for significant partial melting is reported (Williams and Garnero, 1996; Garnero et al., 1998).

Layered structures could also be formed by the presence of iron-rich phases (at the bottom of the D" layer). However, penetration of iron-rich materials is likely to be limited to a very thin layer (less than $\sim 100 \mathrm{~m}$ ) (Poirier and Mouël, 1992) and in which case this effect is not important. A layered structure of former basaltic crust and host mantle, such as the marble-cake mantle as suggested by Allègre and Turcotte (1986), is also possible but the contrasts in elastic constants are not well known. A laminated structure could also be formed by deformation of an MgO-rich layer (Karato, 1998). In this last model, $\mathrm{LPO}$ of $\mathrm{MgO}$ will also be present. The LPO must be the one with the $\{100\}$ plane being horizontal for the net anisotropy to be consistent with seismological observations. In this case, the anisotropic structure will be similar to the one due to LPO without layering.

The analysis presented in this paper provides a physically reasonable framework to interpret seismic anisotropy in the D" layer. LPO of minerals particularly that of $(\mathrm{Mg}, \mathrm{Fe}) \mathrm{O}$ is a likely mechanism of anisotropy in the circum-Pacific regions, whereas both $\mathrm{LPO}$ of $(\mathrm{Mg}, \mathrm{Fe}) \mathrm{O}$ and $\mathrm{SPO}$ of melt pockets could cause anisotropy in the central-Pacific. Common to both is the notion that $V_{\mathrm{SH}}>V_{\mathrm{SV}}\left(V_{\mathrm{SV}}>V_{\mathrm{SH}}\right)$ polarization anisotropy corresponds to horizontal (vertical) flow (if the glide plane in $(\mathrm{Mg}, \mathrm{Fe}) \mathrm{O}$ is $\{100\})$. Therefore seismic anisotropy provides us with key information as to the flow geometry. Thus important constraints will be obtained from seismic anisotropy on the dynamics of interaction of downgoing materials with $\mathrm{CMB}$ and the dynamics of plume generation in the D" layer. However, implications for other physical conditions are different between the two models. LPO of $(\mathrm{Mg}, \mathrm{Fe}) \mathrm{O}$ would imply that the regions of large anisotropy correspond to the regions of high stresses, whereas SPO of melt pockets would imply that these regions correspond to the regions of significant partial melting.

How could one test and distinguish various models by mineral physics and/or seismological observations? From the mineral physics point of view, the most important issue is to investigate the $\mathrm{LPO}$ of $\mathrm{MgO}$ ( or $(\mathrm{Mg}, \mathrm{Fe}) \mathrm{O}$ ) at high pressures and temperatures. Identification of dominant glide plane under extreme conditions will be especially critical. Effects of dynamic recrystallization must also be investigated. From the seismological point of view, the clearest difference between the two models (layered structures and LPO) is the dependence of polarization anisotropy on the direction of wave propagation. The MgO LPO model predicts that the anisotropy has four-fold symmetry. Namely, the nature of 
shear wave polarization depends on azimuth as $\cos 4 \phi$ (Eq. (4)), whereas the model of aligned melt is dominated by the two-fold symmetry (Fig. 8). Measurements of polarization anisotropy at different azimuths are critical to constrain the mechanisms of anisotropy. Such measurements are difficult, however, due to the limited distribution of earthquake sources and currently available stations. New development of seismic stations planned by OHP will provide us with critical data to better understand the dynamics of the D" layer from seismological observations.

Acknowledgments. This research is supported by grants from NSF (EAR-9505451, 9526239, 9706329). I thank Ed Garnero, Barbara Romanowicz and Thorne Lay for discussions on seismological observations and for preprints. Bijaya Karki, Renata Wentzcovitch, Patrick Cordier and David Bercovici are thanked for discussions on elastic anisotropy, slip systems and stress distribution in the D" layer respectively. Thorne Lay and Mark Zimmerman provided useful comments to improve the paper. This paper is based on the talk presented at the OHP workshop in Chiba, Japan. I thank the organizers for inviting me to this workshop.

\section{References}

Aki, K., Seismological evidence for the existence of soft thin layers in the upper mantle under Japan, J. Geophys. Res., 73, 585-594, 1968.

Allègre, C. J. and D. L. Turcotte, Implications of a two-component marblecake mantle, Nature, 323, 123-127, 1986.

Anderson, O. L., Equation of State of Solids for Geophysics and Ceramic Sciences, pp. 405, Oxford University Press, 1995.

Birch, F., The velocity of compressional waves in rocks to 10 kilobars, Part 2., J. Geophys. Res., 57, 2199-2224, 1961.

Buerger, M. J., Translation-gliding in crystals of the $\mathrm{NaCl}$ structural type, Amer. Mineral., 15, 226-238, 1930.

Bussod, G. Y. and J. M. Christie, Textural development and melt topology in spinel lherzolite experimentally deformed at hypersolidus conditions, J. Petrol., Spec. Issue, 17-39, 1991.

Daines, M. J. and D. L. Kohlstedt, Influence of deformation on melt topology in peridotites, J. Geophys. Res., 102, 10,257-10,271, 1997.

Duffy, T. S., R. J. Hemley, and H.-K. Mao, Equation of state and shear strength at multimegabar pressures: Magnesium oxide to $227 \mathrm{GPa}$, Phys. Rev. Lett., 74, 1371-1374, 1995.

Edington, J. W., K. N. Melton, and C. P. Cutler, Superplasticity, Prog. Mater. Sci., 21, 63-170, 1976.

Franssen, R., Rheology of synthetic rocksalt, Ph.D. Thesis, University of Utrecht, pp. 221, 1993.

Garnero, E. J. and T. Lay, Lateral variation in lowermost mantle shear wave anisotropy beneath the north Pacific, J. Geophys. Res., 102, 8121-8135, 1997.

Garnero, E. J., J. Revenaugh, Q. Williams, T. Lay, and L. H. Kellogg, U1tralow velocity zone at the core-mantle boundary, in The Core Mantle Boundary, edited by M. Gurnis, B. A. Buffett, E. Knittle, and M. Wysession, pp. 319-334, AGU Monograph, 1998.

Gay, N. C., Pure shear and simple shear deformation of inhomogeneous viscous fluids, 1. Theory, Tectonophysics, 5, 211-234, 1968.

Honda, S., D. A. Yuen, S. Balachandar, and D. Reuteler, Three-dimensional instabilities of mantle convection with multiple phase transitions, Science, 259, 1308-1311, 1993

Hudson, J. A., Wave speeds and attenuation of elastic waves in material containing cracks, Geophys. J. R. astr. Soc., 64, 133-150, 1981.

Isaak, D. G., R. E. Cohen, and M. E. Mehl, Calculated elastic constants and thermal properties of $\mathrm{MgO}$ at high pressures and temperatures, $J$. Geophys. Res., 95, 7055-7067, 1990.

Jarvis, G. T. and W. R. Peltier, Convection models and geophysical observations, in Mantle Convection, edited by W. R. Peltier, pp. 479-593, Gordon and Breach, New York, 1989

Kaneshima, S. and P. G. Silver, A search for source-side anisotropy, Geophys. Res. Lett., 19, 1049-1052, 1992.

Karato, S., Seismic anisotropy: mechanisms and tectonic implications, in Rheology of Solids and of the Earth, edited by S. Karato and M. Toriumi, pp. 393-422, Oxford University Press, Oxford, 1989

Karato, S., On the Lehmann discontinuity, Geophys. Res. Lett., 19, 22552258, 1992.
Karato, S., Importance of anelasticity in the interpretation of seismic tomography, Geophys. Res. Lett., 20, 1623-1626, 1993.

Karato, S., Phase transformations and rheological properties of mantle minerals, in Earth's Deep Interior, edited by D. J. Crossley, pp. 223-272, Gordon and Breach, New York, 1997.

Karato, S., Seismic anisotropy in the deep mantle, boundary layers and the geometry of mantle convection, PAGEOPH, 151, 565-587, 1998.

Karato, S. and P. Wu, Rheology of the upper mantle: A synthesis, Science, 260, 771-778, 1993.

Karato, S., S. Zhang, and H.-R. Wenk, Superplasticity in the Earth's lower mantle: Evidence from seismic anisotropy and rock physics, Science, 270, 458-461, 1995.

Karato, S., S. Zhang, M. R. Zimmerman, D. L. Kohlstedt, and M. Daines, Towards structural geology of the mantle, PAGEOPH, 151, 589-603, 1998.

Karki, B. B., L. Stixrude, S. J. Clark, M. C. Warren, G. J. Ackland, and J. Crain, Structure and elasticity of $\mathrm{MgO}$ at high pressure, Amer. Mineral., 82, 51-60, 1997a.

Karki, B. B., L. Stixrude, S. J. Clark, M. C. Warren, G. J. Ackland, and J. Crain, Elastic properties of orthorhombic $\mathrm{MgSiO}_{3}$ perovskite at lower mantle pressures, Amer. Mineral., 82, 635-639, $1997 \mathrm{~b}$.

Kendall, J. M. and P. G. Silver, Constraints from seismic anisotropy on the nature of the lowermost mantle, Nature, 381, 409-412, 1996.

Knittle, E. and R. Jeanloz, High-pressure metallization of FeO and implications for the Earth's core, Geophys. Res. Lett., 13, 1541-1544, 1986.

Knittle, E. and R. Jeanloz, Earth's core-mantle boundary: Results of experiments at high pressures and temperatures, Science, 251, 1438-1443, 1991

Kohlstedt, D. L. and M. E. Zimmerman, Rheology of partially molten mantle rocks, Ann. Rev. Earth Planet. Sci., 24, 41-62, 1996.

Lay, T., Q. Williams, and E. J. Garnero, The core-mantle boundary layer and deep earth dynamics, Nature, 392, 461-468, 1998a.

Lay, T., Q. Williams, E. J. Garnero, L. Kellogg, B. Romanowicz, and M. E. Wysession, Seismic wave anisotropy in the D" region and its implications, in The Core Mantle Boundary, edited by M. Gurnis, B. A. Buffett, E. Knittle, and M. Wysession, pp. 299-318, AGU Monograph, 1998b.

Matzel, E., S. E. Sen, and S. P. Grand, Evidence for anisotropy in the deep mantle beneath Alaska, Geophys. Res. Lett., 23, 409-412, 1996.

Maupin, V., On the possibility of anisotropy in the D" layer as inferred from the polarization of diffracted S-waves, Phys. Earth Planet. Inter, 87, 1-32, 1994.

Meade, C., P. G. Silver, and S. Kaneshima, Laboratory and seismological observations of lower mantle isotropy, Geophys. Res. Lett., 22, 12931296, 1995

Montagner, J.-P. and B. L. N. Kennett, How to reconcile body-wave and normal-mode reference Earth model, Geophys. J. Int., 91, 511-520, 1996.

Morgan, W. J., Convection plumes in the lower mantle, Nature, 230, 42-43, 1971.

Musgrave, M. J. P., Crystal Acoustics, pp. 288, Holiden-Day, San Francisco, 1970.

Poirier, J. P. and J.-L. Le Mouël, Does infiltration of core material into the lower mantle affect the observed geomagnetic field?, Phys. Earth Planet. Inter., 73, 29-37, 1992.

Rice, R. W., Hot-working of oxides, in High Temperature Oxides, Part III, edited by A. M. Adler, pp. 2345-2381, Academic Press, New York, 1970.

Ringwood, A. E., Phase transformations and their bearing on the constitution and dynamics of the mantle, Geochim. Cosmochim. Acta, 55, 2083-2110, 1991

Ritsema, J., T. Lay, E. J. Garnero, and H. Benz, Seismic anisotropy in the lowermost mantle beneath the Pacific, Geophys. Res. Lett., 25, 12291232, 1998.

Simmons, G. and H. Wang, Single Crystal Elastic Constants and Calculated Aggregate Properties: A Handbook, pp. 370, The MIT Press, Cambridge, 1971.

Skrotzki, W. and P. Welch, Development of texture and microstructure in extruded ionic polycrystalline aggregates, Tectonophysics, 99, 47-61, 1983.

Stacey, F. D. and D. E. Loper, The thermal boundary layer interpretation of D" and its roe as a plume source, Phys. Earth Planet. Inter, 33, 45-55, 1983.

Tullis, J., J. M. Christie, and D. J. Griggs, Microstructures and preferred orientations of experimentally deformed quartzites, Geol. Soc. Amer. Bull., 84, 297-314, 1973.

Valenzuela, R. and M. E. Wysession, Illuminating the base of the mantle with diffracted waves, in The Core Mantle Boundary, edited by M. Gurnis, B. 
A. Buffett, E. Knittle, and M. Wysession, pp. 57-71, AGU Monograph, 1998.

van der Hilst, R. D., S. Widiyantoro, and E. R. Engdahl, Evidence for deep mantle circulation from global tomography, Nature, 386, 578-584, 1997.

van Houtte, P. and F. Wagner, Development of textures by slip and twinning, in Preferred Orientation in deformed Metals and Rocks: An Introduction to Modern Texture Analysis, edited by H.-R. Wenk, pp. 233-258, Academic Press, New York, 1985.

Vinnik, L., V. Farra, and B. Romanowicz, Observational evidence for diffracted SV in the shadow of the Earth's core, Geophys. Res. Lett., 16, 519-522, 1989.

Vinnik, L., B. Romanowicz, Y. Le Stunff, and L. Makeyeva, Seismic anisotropy in the D" layer, Geophys. Res. Lett., 22, 1657-1660, 1995.

Vinnik, L., L. Breger, and B. Romanowicz, Anisotropic structures at the base of the Earth's mantle, Nature, 393, 564-567, 1998

Wenk, H.-R., C. S. Venkitasubramanyan, D. W. Baker, and F. L. Turner, Preferred orientation in experimentally deformed limestone, Contrib. Mineral. Petrol., 38, 81-114, 1973.

Wenk, H.-R., G. Canova, Y. Bréchet, and L. Flandin, A deformation-based model for recrystallization of anisotropic materials, Acta Mater., 45,
3283-3296, 1997.

Williams, Q. and E. J. Garnero, Seismic evidence for partial melt at the base of the Earth's mantle, Science, 273, 1528-1530, 1996.

Winchester, J. P. and K. C. Creager, Azimuthal anisotropy and abrupt transitions from slow to fast anomalies in the velocity structure of D", Proc. 1997 IRIS Meeting, abstract, 1997.

Woodhouse, J. H. and A. M. Dziewonski, Seismic modelling of the Earth's large-scale three-dimensional structure, Philos. Trans. R. Soc. Lond., A328, 291-308, 1989.

Zhang, S. and S. Karato, Simple shear deformation of $\mathrm{CaTiO}_{3}$ perovskite, Phys. Earth Planet. Inter., 1998 (submitted).

Zhang, S., M. E. Zimmerman, M. J. Daines, S. Karato, and D. L. Kohlstedt, Lattice preferred orientation and melt distribution in experimentally sheared olivine-basalt rocks, EOS, Trans. AGU, 76, 281, 1995.

Zhang, S., S. Karato, and Y. Zhou, Simple shear deformation of olivine aggregates, Tectonophysics, 1998 (submitted).

S. Karato (e-mail: karato@tc.umn.edu) 